\title{
Impairment of some cognitive process in children with reading disability in middle childhood, late childhood, and early adolescence
}

\author{
Fadia Elwan ${ }^{1}$, Shaaban Gaballah ${ }^{1}$ and Abdel Gawad Khalifa ${ }^{2,3^{*}}$ (1)
}

\begin{abstract}
Background: The impairment of cognitive processes in dyslexia is well established, and according to recent studies, this deficit extends to many aspects of cognitive processes. However, these studies have not focused on Planning, Attention, Simultaneous, and Successive processes. Further research is needed concerning cognitive impairment in dyslexia, especially with Arabic-speaking population.

Results: Children with reading disability scored significantly lower in the total and all subscales of Cognitive Assessment System (CAS), Planning, Attention, Simultaneous, and Successive $(P=0.000)$. The children with reading disability obtained worse scores compared with the controls in almost all the subtests of CAS.

Conclusion: The present study highlighted that children with reading disability have difficulties in cognitive processes across the three age groups compared to normal children, which may help in the development of treatment plans and programs for this problem.
\end{abstract}

Keywords: Reading disability, Cognitive functions, PASS theory, Cognitive Assessment System (CAS)

\section{Introduction}

Dyslexia is a developmental disorder affecting the efficient acquisition of literacy skills, present in $5-17 \%$ of the population; it influences reading accuracy and fluency, as well as spelling and composition skills [1].

Developmental dyslexia is characterized by difficulties in word reading and spelling despite normal intelligence and adequate formal education, and much research on dyslexia demonstrated that it involves multiple cognitive-linguistic deficits; the majority of these studies focused on phonological processing, including phonological awareness, rapid automatized naming, and verbal short-term memory in most languages tested [2].

Cognitive correlates of word reading difficulty which comprise the majority of reading disability (RD) cases

\footnotetext{
* Correspondence: gawad1010@yahoo.com

${ }^{2}$ Institute of Psychiatry, Ain Shams University, Cairo, Egypt

${ }^{3}$ Department of Psychiatry, Ain Shams University Hospitals, Cairo, Egypt

Full list of author information is available at the end of the article
}

have been studied extensively. Word reading difficulty is caused by a phonological deficit, encompassing difficulties with phonological awareness, speeded lexical retrieval, and verbal short-term memory [3, 4].

Researchers have found that verbal short-term memory performance contributes unique variance to the prediction of word reading skill, even when controlling for phonological awareness or naming speed but always in addition to phonological awareness $[5,6]$.

Some evidence suggests that central executive processes, called executive function, also play a role in reading disability separate from verbal short-term memory [7].

Intelligence, assessed with traditional IQ tests, has been heavily criticized as insufficient to account for individual differences in reading [3]. It has also been argued that when intelligence is operationalized in terms of cognitive processes, it enhances our understanding of reading [8].

Das, Naglieri, and Kirby proposed a new conceptualization of cognitive processing based on "planning," "attention," 
"simultaneous processing," and "successive processing" (PASS). Planning provides cognitive control and use of processes and knowledge, intentionality, and self-regulation to achieve a desired goal, whereas attention provides focused, selective cognitive activity over time. Simultaneous processing allows an individual to integrate separate stimuli into a single whole or group, and successive processing integrates stimuli into a specific serial order that forms a chain-like progression $[9,10]$.

This theory takes the cognitive processing perspective of one's abilities, which assumes that PASS processes are the basic cognitive functions that allow students to perform a variety of academic tasks [11].

It is important to remember that all PASS processes are involved in most things people do. Says reading as an example, Planning is needed for organizing how the task will be completed and for exerting impulse control. The ability in differentiating the letters or words is that it has a heavy demand for Attention. Simultaneous processing requires the individual to connect the meaning of each word in the sentences or each of the meaning of each sentence in the passage. Finally, the Successive process needs the person to obtain the ability to identify orderly words from the sentence or the ideas of the sentence in the passage [12].

\section{Hypothesis}

We hypothesized that children with reading disability would show an impairment in cognitive processes compared with controls.

\section{Aim of the study}

This study aimed to ascertain whether children with reading disability show different performance and deficits in cognitive processes compared with well-matched apparently normal controls.

\section{Subjects and methods Participants}

The sample for the current study consisted of 180 male students, who were divided into two groups.

\section{A: group of the participants with reading disabilities}

This group is formed from 90 males, whose intelligence quotients ranged between 90 and 110 on the abbreviated version of Wechsler Intelligence Scale for Children. They were selected from the Institute of Psychiatry, Ain Shams University. The participants were diagnosed with reading disabilities by a psychiatrist according to the Diagnostic and Statistical Manual of Mental Disorders, 5th ed. (DSM-V) criteria for reading disability (Table 1 ). The participants were not suffering from any other behavioral or emotional disorders. The participants' age ranged between 7 and 15 years old; they were divided into three subgroups according to their chronological age:

1. Group of middle childhood stage: the age range of the participants was 7-9 years old with a mean age of 8.26 and a standard deviation of 0.54 . They were enrolled in primary 2 and primary 3 .

2. Group of late childhood stage: the age range of the participants was 9-12.5 years old with a mean age of 10.62 and a standard deviation of 0.77 . They were enrolled in primary 4 and primary 6.

3. Group of early adolescence stage: the age range of the participants was $12.5-15$ years old with a mean age of 13.84 and a standard deviation of 0.83 . They were enrolled in the first preparatory grade till the third preparatory grade.

\section{B: group of the participants with normal reading}

This group is formed from 90 males whose intelligence quotients ranged between 90 and 110 on the abbreviated version of Wechsler Intelligence Scale for Children. They were selected from schools which are equal to the schools of the participants with reading disability (Table 2). The participants were not suffering from any behavioral or emotional disorders. The participants' age ranged between 7 and 15 years old; they were divided into three subgroups according to their chronological age:

1. Group of middle childhood stage: the age range of the participants was 7-9 years old with a mean age of 8.39 and a standard deviation of 0.52 . They were enrolled in primary 2 and primary 3 .

2. Group of late childhood stage: the age range of the participants was 9-12.5 years old with a mean age of 10.59 and a standard deviation of 0.91 . They were enrolled in primary 4 and primary 6.

3. Group of early adolescence stage: the age range of the participants was $12.5-15$ years old with a mean

Table 1 The characteristics of the participants with reading disability

\begin{tabular}{|c|c|c|c|c|c|c|}
\hline & \multicolumn{2}{|c|}{ Middle childhood, $N=30$} & \multicolumn{2}{|c|}{ Late childhood, $N=30$} & \multicolumn{2}{|c|}{ Early adolescence, $N=30$} \\
\hline & $\bar{M}$ & SD & $\bar{M}$ & SD & $\bar{M}$ & SD \\
\hline Age & 8.26 & 0.54 & 10.26 & 0.77 & 13.93 & 0.79 \\
\hline IQ & 100.10 & 3.40 & 100.13 & 3.05 & 101.83 & 3.71 \\
\hline Socio-economic level & 24.20 & 3.48 & 23.86 & 4.25 & 24.30 & 3.41 \\
\hline
\end{tabular}


Table 2 The characteristics of the participants with normal reading

\begin{tabular}{|c|c|c|c|c|c|c|}
\hline & \multicolumn{2}{|c|}{ Middle childhood, $N=30$} & \multicolumn{2}{|c|}{ Late childhood, $N=30$} & \multicolumn{2}{|c|}{ Early adolescence, $N=30$} \\
\hline & $M$ & SD & $\bar{M}$ & SD & $M$ & SD \\
\hline Age & 8.39 & 0.52 & 10.59 & 0.91 & 13.93 & 0.79 \\
\hline IQ & 100.96 & 3.96 & 100.43 & 5.04 & 101.83 & 3.71 \\
\hline Socio-economic level & 24.03 & 3.71 & 23.73 & 4.11 & 24.30 & 3.41 \\
\hline
\end{tabular}

age of 13.93 and a standard deviation of 0.79 . They were enrolled in the first preparatory grade till the third preparatory grade.

The following conditions were considered while selecting the entire participants:

- Normal senses

- The absence of any medical diseases

- The equality of the socio-economic level between the two groups

- The equality of the educational system between the two groups

- The equality of students' number in each educational grade between the two groups

\section{Tools}

The sample studied was subjected to the following:

1. The abbreviated version of Wechsler Intelligence Scale for Children (WISC).

2. Fahmy and El-Sherbini's Social Classification Scale: participants were classified into social classes 1, 2, 3 , and 4 according to an Egyptian classification developed by Fahmy and El-Sherbini [13]. The classification is based on the following parameters: education of the father, education and work of the mother, income, crowding index, and sanitation. The study was approved by the Ethics Committee of the Institute of Psychiatry, Ain Shams University.

\section{Cognitive Assessment System}

The Cognitive Assessment System (CAS) is an individually administered test for children aged 5-17 years designed to measure four basic psychological processes. The CAS is organized according to the PASS Theory and comprised of four scales: Planning, Attention, Simultaneous, and Successive, each set at a mean of 100 and SD of 15 . The eight-subtest Basic Battery was used in this study. The CAS was standardized on a sample of 2200 children aged 5-17 years who were selected to reflect the demographics of the USA. The average Basic Battery reliability coefficients are as follows: Full Scale (.87), Planning (.85), Attention (.84), Simultaneous (.90), and Successive (.90) [14].

The CAS measures individual differences in cognition by examining the four distinct but interrelated cognitive processes articulated in the PASS theory of intelligence: planning, attention, simultaneous processing, and successive processing [15]. Components of the CAS battery reflect the distinction between (a) higher-order control processes used in planning and monitoring task performance (i.e., planning and attention) and (b) information-processing components that involve the movement of information through working memory (i.e., simultaneous and successive processing). For the present investigation, we used the Basic Battery, which consists of two subtests for each of the four PASS cognitive processes. Planning subtests require individuals to engage in multiple self-regulatory processes such as creating, applying, monitoring, and revising plans of action while solving novel tasks. The attention subtests require the detection of particular stimuli and the inhibition of responses to distracting stimuli. Simultaneous processing subtests require individuals to integrate separate stimuli into a conceptual group or whole. Successive processing subtests require individuals to comprehend meaning as it is derived from the order of information [16].

Table 3 Cognitive Assessment System: dyslexic vs. controls (total sample)

\begin{tabular}{|c|c|c|c|c|c|c|}
\hline \multirow{2}{*}{$\begin{array}{l}\text { Sample CAS } \\
\text { subscales }\end{array}$} & \multicolumn{2}{|c|}{ Dyslexic group $(N=90)$} & \multicolumn{2}{|c|}{ Control group $(N=90)$} & \multirow[t]{2}{*}{$F$} & \multirow[t]{2}{*}{ Sig. } \\
\hline & $\bar{M}$ & SD & $\bar{M}$ & SD & & \\
\hline Planning & 81.81 & 12.51 & 93.86 & 10.97 & -6.86 & 0.000 \\
\hline Attention & 78.12 & 12.07 & 91.50 & 10.99 & -7.72 & 0.000 \\
\hline Simultaneous & 73.70 & 12.74 & 96.28 & 12.68 & -11.91 & 0.000 \\
\hline Successive & 89.12 & 11.09 & 102.90 & 10.89 & -8.40 & 0.000 \\
\hline Total & 74.40 & 10.01 & 94.92 & 8.96 & -9.94 & 0.000 \\
\hline
\end{tabular}

The overall subtests measure Planning, Attention, Simultaneous, and Successive processes highly significant 
Table 4 Cognitive Assessment System: dyslexic vs. controls (middle childhood)

\begin{tabular}{|c|c|c|c|c|c|c|}
\hline \multirow{2}{*}{$\begin{array}{l}\text { Sample CAS } \\
\text { subscales }\end{array}$} & \multicolumn{2}{|c|}{ Dyslexic group $(N=30)$} & \multicolumn{2}{|c|}{ Control group $(N=30)$} & \multirow[t]{2}{*}{$F$} & \multirow[t]{2}{*}{ Sig. } \\
\hline & $\mathrm{M}$ & SD & M & SD & & \\
\hline Planning & 79.50 & 8.77 & 91.50 & 9.94 & -4.95 & 0.000 \\
\hline Attention & 77.23 & 13.63 & 89.50 & 9.75 & -4.00 & 0.000 \\
\hline Simultaneous & 72.60 & 13.73 & 93.16 & 13.41 & -5.86 & 0.000 \\
\hline Successive & 86.40 & 11.54 & 101.23 & 11.66 & -4.94 & 0.000 \\
\hline Total & 73.46 & 12.79 & 94.40 & 10.42 & -6.94 & 0.000 \\
\hline
\end{tabular}

The overall subtests measure Planning, Attention, Simultaneous, and Successive processes highly significant

\section{Data processing and statistical analysis}

All data were recorded and entered into a statistical package on a compatible computer and varied. The analysis was carried out using an SPSS, version 21. The results were tabulated, grouped, and statistically analyzed using the following tests.

Descriptive statistics (for quantitative data), as we used mean $(X)$ and $\pm \mathrm{SD}$, chi-square tests for socio-economic states, and $t$ test, were used to test for significance of an independent variable (to compare between two independent means).

\section{Results}

There was no statistically significant difference in the social class between the two groups, with the majority of the children in the dyslexic group in the middle social class, middle childhood (56.7\%), late childhood (43.3\%), and early adolescence (60\%), and the majority of the participants in the control group also in the middle social class middle childhood (53.3\%), late childhood (46.6\%), and early adolescence $(60 \%)$, chi-square $=14.952$ not significant.

\section{Performance in cognitive functions}

Children with reading disability (total sample) scored significantly lower on all subscales of the CAS $(P=0.000)$ (Table 3). On almost all domains of the CAS, the control group through the three age stages (middle childhood, late childhood, and early adolescence) obtained a statistically significantly higher mean score than did the children with reading disability $(P=0.000)$ (Tables $3,4,5$, and 6).

\section{Discussion}

The efficacy of PASS as a theoretical guide for identifying cognitive processes related to academic achievement and learning disabilities $[17,18]$ has been demonstrated. The results of the present study provide support to PASS theory as an interactional model of cognitive processes that can discriminate between children with reading disability and average readers. Additionally, Planning, Attention, Successive, and Simultaneous processing skills have been found in capable readers and deficient in students with reading disabilities. The results of the present study provide support to the PASS, Planning, Attention, Simultaneous, and Successive, cognitive processes as being deficient in children with reading disability and well developed in average readers [19].

Our study showed that there was a statistically significant difference in the performance in CAS battery between children with reading disability and controls in almost all domains (Planning, Attention, Simultaneous, and Successive processes). Differences between children with reading disability and control participants were supported by some findings from the literature.

Kirby et al. [18] demonstrated how the PASS model of cognition can be applied to the understanding of cognitive processing differences between students with reading disabilities and typically achieving students. Sixty elementaryage children were administered subtests from the DN: CAS and select subtests from the Woodcock-Johnson Test of Achievement.

Early studies found that reading was significantly related to both successive and simultaneous processes (i.e., the

Table 5 Cognitive Assessment System: dyslexic vs. controls (late childhood)

\begin{tabular}{|c|c|c|c|c|c|c|}
\hline \multirow{2}{*}{$\begin{array}{l}\text { Sample CAS } \\
\text { subscales }\end{array}$} & \multicolumn{2}{|c|}{ Dyslexic group $(N=30)$} & \multicolumn{2}{|c|}{ Control group $(N=30)$} & \multirow[t]{2}{*}{$F$} & \multirow[t]{2}{*}{ Sig. } \\
\hline & M & SD & $\mathrm{M}$ & SD & & \\
\hline Planning & 81.06 & 13.66 & 91.60 & 10.76 & -3.31 & 0.002 \\
\hline Attention & 78.20 & 12.54 & 92.13 & 11.10 & -4.55 & 0.000 \\
\hline Simultaneous & 73.50 & 12.71 & 97.20 & 10.08 & -7.99 & 0.000 \\
\hline Successive & 89.39 & 11.86 & 103.36 & 9.37 & -5.09 & 0.000 \\
\hline Total & 74.33 & 8.31 & 94.60 & 9.13 & -8.98 & 0.000 \\
\hline
\end{tabular}

The overall subtests measure Planning, Attention, Simultaneous, and Successive processes highly significant 
Table 6 Cognitive Assessment System: dyslexic vs. controls (early adolescence)

\begin{tabular}{|c|c|c|c|c|c|c|}
\hline \multirow{2}{*}{$\begin{array}{l}\text { Sample CAS } \\
\text { subscales }\end{array}$} & \multicolumn{2}{|c|}{ Dyslexic group $(N=30)$} & \multicolumn{2}{|c|}{ Control group $(N=30)$} & \multirow[t]{2}{*}{$F$} & \multirow[t]{2}{*}{ Sig. } \\
\hline & $\mathrm{M}$ & SD & M & SD & & \\
\hline Planning & 84.66 & 14.19 & 98.50 & 11.02 & -4.15 & 0.000 \\
\hline Attention & 79.20 & 15.09 & 92.86 & 12.08 & -4.55 & 0.000 \\
\hline Simultaneous & 75.00 & 12.04 & 98.50 & 14.01 & -6.96 & 0.000 \\
\hline Successive & 91.66 & 9.43 & 104.10 & 11.64 & -4.54 & 0.000 \\
\hline Total & 76.10 & 9.92 & 94.80 & 8.30 & -7.91 & 0.000 \\
\hline
\end{tabular}

The overall subtests measure Planning, Attention, Simultaneous, and Successive processes highly significant

integration of the reading stimuli in either a sequential or simultaneous manner) [20-22]. Simultaneous and successive processing tasks have correlated significantly with measures of reading comprehension [23-26] and reading decoding [27]. These findings suggest that high reading achievement necessitates adequate skill development in both simultaneous and successive processing.

Planning and attention have also been shown to correlate significantly with reading [28]. Planning has been related to reading decoding and reading comprehension in studies with elementary school-aged students and was reported to become more highly correlated with reading achievement as students matured [17, 29]. Ramey's study with high school students also supported the importance of planning with a variety of reading tasks.

Components of the PASS theory can aid in understanding a child's skill at reading. For example, it has been argued that the planning function allows the child, when reading a word, to use alternative strategies and then to monitor and evaluate those strategies. The attentional function maintains an optimal level of arousal necessary for a child to discriminate among stimuli, focus and direct behavior, and activate the planning and coding cognitive processes. The successive cognitive process keeps every piece of information in its correct order, whereas the simultaneous process combines pieces of information to produce a single or integrated code. It has been suggested that simultaneous processing is involved in holistic word recognition and successive processing in the phonic analysis of a word [30, 31].

Finally, the good readers showed solid performance on all tasks, suggesting intact planning, attention, simultaneous, and successive processes, while the reading disability group demonstrated deficits in their planning, attention, simultaneous, and successive processes; this type of cognitive profiling could provide psychologists with a functional analysis of cognitive strength and weakness, and information about potential overlap of cognitive processing deficits in reading disability and areas of need can then be better defined and targeted for special educational programming; skills can be observed, measured, and potentially linked to improvements in curriculum-based achievement.

\section{Conclusion}

The aim of the present study was to investigate the cognitive impairment of children with reading disability. A sample of 180 Egyptian boy students from grade 2 to grade 9 participated in this study, including 90 students who have a reading disability and 90 normal control, matched in age, socio-economic states, and IQ. They were administered with the Cognitive Assessment System (CAS), which was used to measure the planningattention-simultaneous processing-successive processing (PASS). The results showed that reading-disabled students have deficits in planning-attention-simultaneous processing-successive processing (PASS) compared to normal children.

\section{Strength and limitations}

Although our study was one of only a few to compare cognitive functions in children with reading disability and normal controls, our study was limited by the sample size; thus, caution should be exercised in the generalization of the results of this study, and more research should be carried out on larger samples to replicate these results.

Another limitation of our study was that it was cross-sectional in nature, and although it helped identify associations, it was difficult to infer causality in relationships. A longitudinal study would help answer many questions in this area.

It must also be taken into consideration that the study was conducted on a sample of males only, so it is difficult to generalize their results to the general public population.

\section{Abbreviations}

CAS: Cognitive Assessment System; DSM-V: Diagnostic and Statistical Manual of Mental Disorders, 5th ed; PASS: Planning, Attention, Simultaneous,

Successive; RD: Reading disability

\section{Acknowledgements}

Not applicable

Authors' contributions

FE and SG conceived and designed the study and analyzed the data. AK wrote the first draft of the manuscript, interpreted the data, and wrote the final manuscript. All authors agreed with the results and conclusions of this article. All authors read and approved the final manuscript.

Funding

We do not have a funding source. 


\section{Availability of data and materials}

All data and materials are available.

\section{Ethics approval and consent to participate}

The study was approved by the Ethics Committee of the Institute of Psychiatry, Ain Shams University. The child and the parent agreed to participate in the research, after receiving detailed information about the research. Written informed consent for participation in the study was obtained (participants are children under 16 years old)

\section{Consent for publication}

All authors have approved the manuscript for publication.

\section{Competing interests}

The authors declare that they have no competing interests.

\section{Author details}

'Psychology Department, Faculty of Arts, Cairo University, Cairo, Egypt. ${ }^{2}$ Institute of Psychiatry, Ain Shams University, Cairo, Egypt. ${ }^{3}$ Department of Psychiatry, Ain Shams University Hospitals, Cairo, Egypt.

Received: 28 June 2019 Accepted: 8 July 2019

Published online: 23 July 2019

\section{References}

1. Morkena F, Helland T, Hugdahl K, Specht K (2017) Reading in dyslexia across literacy development: a longitudinal study of effective connectivity. Neuro Image 144:92-100

2. Wang L, Liu D, Chung KK, Yang H (2017) Development of lexical tone awareness in Chinese children with and without dyslexia. Contemp Educ Psychol 49:203-214

3. Catts HW, Hogan TP, Fey ME (2003) Subgrouping poor readers on the basis of individual differences in reading-related abilities. J Learn Disabil 36:151-164

4. Vellutino FR, Fletcher JM, Snowling MJ, Scanlon DM (2004) Specific reading disability (dyslexia): what have we learned in the past four decades? J Child Psychol Psychiatry 45:2-40

5. de Jong PF (1998) Working memory deficits of reading disabled children. J Exp Child Psychol 70:75-96

6. Ramus F, Szenkovits G (2009) Understanding the nature of the phonological deficit. In: Pugh K, McArdle P (eds) How children learn to read: current issues and new directions in the integration of cognition, neurobiology, and genetics of reading and dyslexia research and practice. Psychology Press, New Yor, pp 153-169

7. Swanson HL, Howell M (2001) Working memory, short-term memory, and speech rate as predictors of children's reading performance at different ages. J Educ Psychol 93:720-734

8. Naglieri JA, Das JP (2005) Planning Attention, Simultaneous, Successive (PASS) theory: a revision of the concept of intelligence. In: Flanagan DP, Harrison PL (eds) Contemporary intellectual assessment: Theories, tests, and issues. Guilford Press, New York, pp 120-135

9. Das JP, Naglieri JA, Kirby JR (1994) Assessment of cognitive processes: the PASS theory of intelligence. Allyn \& Bacon, Boston

10. Naglieri JA, Das JP (1997) Cognitive Assessment System interpretive handbook. Riverside, Itasca

11. Dan Cai D, Li QW, Deng CP (2013) Cognitive processing characteristics of 6th to 8th grade Chinese students with mathematics learning disability: relationships among working memory, PASS processes, and processing speed. Learn Individ Differ 27:120-127

12. Keat OB, Ismail KB (2010) The PASS cognitive functions of children with reading difficulties: a Malaysian study. Procedia Soc Behav Sci 5:2182-2193

13. Fahmy S, El-Sherbini AF (1988) Determining simple parameters for social classification for health research. Bull High Inst Pub Health 13:95-108

14. Naglieria JA, Goldsteinb S, Delauder BY, Schwebach A (2005) Relationships between the WISC-III and the Cognitive Assessment System with Conners' rating scales and continuous performance tests. Arch Clin Neuropsychol 20:385-401

15. Naglieri JA (1999) Essentials of CAS assessment. Wiley, New York

16. Fein EC, Day EA (2004) The PASS theory of intelligence and the acquisition of a complex skill: a criterion-related validation study of Cognitive Assessment System scores. Personality Individ Differ 37:1123-1136
17. Naglieri JA, Das JP (1987) Construct and criterion-related validity of planning simultaneous, and successive cognitive processing tasks. J Psychoeduc Assess (4):353-363

18. Kirby JR, Booth CA, Das JP (1996) Cognitive processing and IQ in reading disability. J Spec Educ 29(4):442-456

19. Kortteinen $H$, Nprhi $V$, Ahonen $T$ (2009) Does IQ matter in adolescents' reading disability? Learn Individ Differ 19:257-261

20. Das JP, Mensink D (1989) K-ABC simultaneous-sequential scales and prediction of achievement in reading and mathematics. J Psychoeduc Assess 7:103-111

21. Das JP, Snart F, Mulcahy RF (1982) Reading disability and its relation to information integration. In: Das JP, Mulcahy RF, Wall AE (eds) Theory and research in learning disabilities

22. (pp. 85-110). New York: Plenum. Leong CK. Cognitive patterns of "retarded" and below-average readers. Contemp Educ Psychol, 1980; 5, 101-117.

23. Kirby JR (1982) Cognitive processes, school achievement, and comprehension of ambiguous sentences. J Psycholinguist Res 11:485-499

24. Kirby JR, Robinson GL (1987) Simultaneous and successive processing in reading disabled children. J Learn Disabil 20:243-252

25. Leong CK (1984) Cognitive processing, language awareness, and reading in grade 2 and grade 4 children. Contemp Educ Psychol 9:369-383

26. McRae SG (1986) Sequential-simultaneous processing and reading skills in primary grade children. J Learn Disabil 19:509-511

27. Das JP, Cummins JP (1982) Language processing and reading disability. Adv Learn Behav Difficult 1:3-24

28. Parrila RK, Kendrick ME, Papadopoulos TC, Kirby JR (1999) Efficacy of cognitive reading remediation program for at-risk children in grade 1. Develop Disabil Bull 27(2):1-31

29. Leong CK, Cheng SC, Das JP (1985) Simultaneous-successive syntheses and planning in Chinese readers. Int J Psychol 20:19-31

30. Kirby JR, Williams NH (1991) Learning problems: a cognitive approach. Toronto: Kagan and Woo

31. Das J (1993) Differences in cognitive processes of children with reading disabilities and normal readers. Develop Disabil Bull 21:42-59

\section{Publisher's Note}

Springer Nature remains neutral with regard to jurisdictional claims in published maps and institutional affiliations.

\section{Submit your manuscript to a SpringerOpen ${ }^{\circ}$ journal and benefit from:}

- Convenient online submission

- Rigorous peer review

- Open access: articles freely available online

High visibility within the field

- Retaining the copyright to your article

Submit your next manuscript at $>$ springeropen.com 